\title{
A paraganglioma presenting with a giant mediastinal mass: A case report
}

\author{
Ercan Gündüz ${ }^{\mathrm{a}}$, Recep Dursun ${ }^{\mathrm{a} *}$, Ahmet Erbey ${ }^{\mathrm{b}}$, Mustafa İçera, Yılmaz Zengina ${ }^{\mathrm{a}}$, Cahfer Güloğlu ${ }^{\mathrm{a}}$ \\ ${ }^{a}$ Department of Emergency Medicine, Faculty of Medicine, Dicle University, Diyarbakır, Turkey \\ ${ }^{b}$ Department of Thoracic Surgery, Faculty of Medicine, Dicle University, Diyarbakır, Turkey
}

\section{ARTICLE INFO}

Article History

Received 24/10/2013

Accepted $\quad 26 / 11 / 2013$

\section{* Correspondence to:}

Recep Dursun

Department of Emergency Medicine,

Faculty of Medicine,

Dicle University,

Diyarbakır, Turkey

e-mail: drrecepdursun@hotmail.com

\section{ABSTRACT}

Paragangliomas are considerably rare and usually benign chromaffin cell tumors originating from sympathetic ganglia outside adrenal medulla. They are usually asymptomatic and detected incidentally. Tumor spread is through both lymphatic and hematogenous route. However, they may cause symptoms when excessively grown. They can be successfully treated with surgery even if they reach a gigantic size when they are diagnosed at an early period and lack metastases. From this perspective, early diagnosis and treatment of them is of great importance. In this study we present a patient presenting to emergency department with dyspnea and diagnosed with a giant paraganglioma in the anterior mediastinum.

J. Exp.Clin.Med., 2014; 31:115-117

\section{Keywords:}

Adrenal medulla

Dyspnea

Mediastinal mass

(C) 2014 OMU

Paraganglioma

\section{Introduction}

Paragangliomas (PG) are quite rare tumors originating from neural crest cells in autonomic nervous system. Also called glomus tumor, chemodectoma, carotid body tumor, or receptoma, these tumors are rare and slowly growing neuroendocrine tumors (Sobol and Dailey, 1990). They are most commonly located at the bifurcation of common carotid artery, jugular foramen, aortic arch, and retroperitoneum (Lee et al., 2006). Tumors arising from adrenal medulla are called pheochromocytoma. Tumors originating from paraganglia in other regions are collectively called PG. PGs originating from parasympathetic system are usually non-functional while those arising from sympathetic ganglia are functional and secrete catecholamines (Rha et al., 2003). Majority of PGs are benign. Approximately $10 \%$ are malignant. About $20-42 \%$ of these tumors metastasize whereas only $2-10 \%$ of adrenal pheochromocytomas do metastasize (Soylu et al., 2009). Tumor spread is through both lymphatic and hematogenous route. The most common metastasis sites are regional lymph nodes, bone, liver, and lungs (Soylu et al., 2009). In this report a patient who presented with a giant mass in the anterior mediastinum and was diagnosed with PG in biopsy was discussed with review of the relevant literature.

\section{Case report}

A 49-year-old woman patient with a 2-year history of malaise, loss of appetite, and weight loss presented to emergency department with progressive dyspnea for the last two weeks. She told that she had lost approximately $10 \mathrm{~kg}$ weight within the last three months. She had been admitted to several hospitals for these complaints several times but had not benefited from any treatment. Her past history was remarkable for hypertension. Her family history was not remarkable for any diseases. On physical examination she was in moderate general condition and alert. Her blood pressure was $140 / 90 \mathrm{mmHg}$ and pulse rate was $104 \mathrm{bpm}$. Laboratory parameters were as follows: Hemoglobin: 12.7 g/dL, Hematocrit: 37\%, White blood cell: $8.900 \mathrm{~K} / \mathrm{uL}$, Platelet: $177000 \mathrm{~K} / \mathrm{uL}$, Erythrocyte sedimentation rate: 57, C-reactive protein: $24 \mathrm{mg} / \mathrm{dL}$, glucose: $105 \mathrm{mg} / \mathrm{dL}$, urea: 28 $\mathrm{mg} / \mathrm{dL}$, creatinine: $1.2 \mathrm{mg} / \mathrm{dL}$, aspartate transaminase: 57 $\mathrm{U} / \mathrm{L}$, alanine transaminase: $34 \mathrm{U} / \mathrm{L}$, lactate dehydrogenase: 
$574 \mathrm{U} / \mathrm{L}$, albumin: $2.3 \mathrm{gr} / \mathrm{dL}$, and calcium: $7.2 \mathrm{mg} / \mathrm{dL}$. Postero-anterior chest X-Ray revealed widening of anterior mediastinum. A chest computerized tomography (CT) was obtained which showed high mediastinal, prevascular, right hilar, and subcarinal lymph nodes reaching a short diameter of $1.4 \mathrm{~cm}$. On the left side, CT demonstrated a lobulated mass lesion of $13 \times 7.3 \mathrm{~cm}$ that was filling anterior mediastinum, extending along aortic arch, enveloping pulmonary trunk, and having an indentation to the upper lobe of left lung. Areas of fat between the mass and the aortic arch were erased from place to place. The mass was invading parietal pericardium from the left anterolateral aspect (Figures 1 and 2). The patient was admitted to thoracic surgery department for investigation of the etiology of the mass. Her thyroid function tests (TSH, FT3, FT4) were normal. Her blood gas analysis revealed the following values: $\mathrm{pH}: 7.32, \mathrm{PCO}_{2}: 44, \mathrm{PO}_{2}: 72, \mathrm{HCO} 3$ : $19.6 \mathrm{mEq} / \mathrm{L}$. Tests directed at the etiology of hypertension revealed normal vanyl mandelic acid (VMA), metanephrine, normetanephrine, adrenaline, noradrenaline, 5-Hydroxyindole Acetic Acid (5-HIAA), and other catecholamin levels. Transthoracic biopsy from the mass was reported as paraganglioma. An I-131- metaiodobenzylguanidine (MIBG) scintigraphy was performed for detection of the primary focus and metastases. No distant metastasis was detected. The patient was considered inoperable owing to pericardial invasion. She was recommended chemotherapy by the medical oncology department and radiotherapy by the radiation oncology department. However, she denied recommended therapies and was discharged after being informed about her diseases.

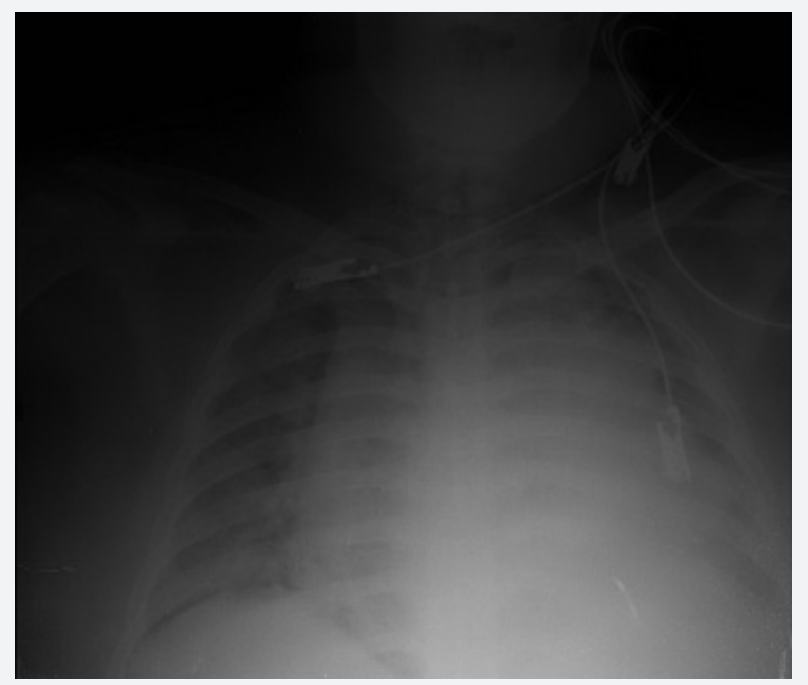

Fig. 1. Mediastinal widening on P-A chest X-Ray

\section{Discussion}

Paraganglioma is a rare, slowly growing, benign, neurogenic tumor commonly originating from sympathetic ganglionic cells, and rarely from adrenal medulla and sympathetic and peripheral nerves (Ekici et al., 2011). They most commonly originate from retroperitoneum and chemoreceptor organs around great vessels. Those located retroperitoneally arise in childhood, are generally functional, have malignant course in $40-50 \%$ of patients, and exhibit a slow progression (Tekin et al., 2008).

PGs are most commonly diagnosed at the 4th decade with

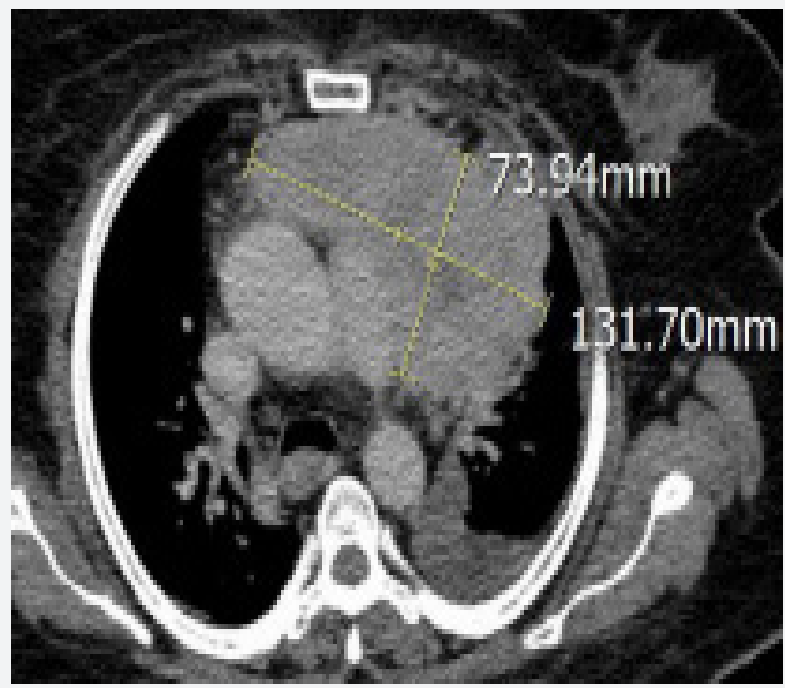

Fig. 2. Thoracic CT demonstrates a giant mass filling anterior mediastinum and invading pericardium on the left side.

similar rates in both genders. In our case the tumor originated from the surrounding of the great vessels, and became symptomatic at fourth decade only after having reached a large size.

Paragangliomas secreting catecholamines are seen in $0.01-0.001 \%$ of the general population although they are responsible from $1 \%$ of hypertension cases in adults (Ekici et al., 2011). Our patient had a 10-year history of hypertension and her blood and urinary catecholamines and VMA level were normal. Therefore, we did not consider that hypertension in this patient was due to PG but rather it was of essential type.

Extraadrenal paragangliomas, unlike those of adrenal origin, usually do not produce clinical symptoms associated with hormone release and catecholamine production. Nonfunctional PGs are associated with considerable difficulty related with preoperative diagnosis (Soylu et al., 2009). PGs are benign tumors although they can metastasize and behave locally aggressive. Risk factors associated with PGs have been reported as tumor size and metastatic disease. Fifteen years survival rate is $100 \%$ in tumors below $5 \mathrm{~cm}$ size. It has been shown that adrenal and extra-adrenal PGs were not different with respect to survival rate and disease-free survival rate (Ekici et al., 2011). Our patient had no clinical symptoms associated with hormone and catecholamine release. Although she was symptomatic for two years, her tumor could only be detected and diagnosed once it reached a gigantic size and caused compressive symptoms because the tumor was non-functional. Absence of distant metastases despite gigantic size of the tumor suggested a benign character although our patient had signs of local invasion.

Diagnosis of PGs is possible through detecting of increase of blood and urinary catecholamine and VMA levels as well as demonstration of the presence of a mass with radiological studies (CT, MRI,I131-MIBG scintigraphy, and angiography). The diagnosis is usually made with needle aspiration or open biopsy (Adsan et al., 2004). Treatment of PGs involves surgery, chemotherapy, radiotherapy, and recently Iodine131-metaiodobenzylguanidine (I-131-MIBG). MIBG has a sensitivity of $77-90 \%$ for detection of multiple tumors and 
recognition of small lesions not visible on CT (Sofikerim et al., 2006). Chemotherapy and radiotherapy are utilized in cases with potential perioperative morbidity and mortality associated with mass resection owing to organ involvement, or in cases where a curative surgery is not possible. Patients with metastases have a mean survival of less than three years. PG cases with metastatic disease may be administered chemotherapeutic agents including cyclophosphamide, vincristine, and dacarbazine. Symptoms of local compression can be treated with radiotherapy for palliation (Lee et al., 2006). Since our patient was considered inoperable as a result of pericardial invasion, she already lost chance for surgical cure. She was recommended chemotherapy and radiotherapy for palliation but she denied such treatments, and therefore we could not follow her survival.

\section{Conclusion}

Paragangliomas may not be symptomatic before reaching a large size. PGs can be successfully treated with surgery even if they reach a gigantic size when they are diagnosed at an early period and lack of metastases. From this perspective, early diagnosis and treatment of PGs are of great importance.

\section{REFERENCES}

Adsan, Ö., Koşan, M., Seçkin, S., Han, Ö., Kaygısız, O., 2004. Böbrek metanefrik adenomu ve mesane paragangliyomunun birlikteliği: Olgu sunumu. Türk Üroloji Dergisi. 30, 479-481.

Ekici, K., Mayadağl1, A., Karabulut, G.Ş., Özdemir Z., Oruç, A.F, Kayahan, S., Ceylaner, B.B., 2011. Metastatik paragangliom olgusunda tedavi yaklaşımı: Olgu sunumu. J. Kartal TR. 22, 89-93.

Lee, K.Y., Oh,Y.W., Noh, N.J., Lee, Y.J., Yong, H.S., Kang, E.Y., et al. 2006. Extra adrenal paragangliomas of the body: Imaging features: AJR. 187, 492-504.

Rha, S.E., Byun, J.Y., Jung, S.E., Chun, H.J., Lee, H.G., Lee, J.M., 2003. Neurogenic tumors in the abdomen: Tumor types and imaging characteristics. Radiographics. 23, 29-43.

Sobol, S.M., Dailey, J.C., 1990. Familial multiple cervical paragangliomas: Report of a kindred and review of the literature. Otolaryngol Head Neck Surg. 102, 382-390.

Sofikerim, M., Tatlışen, A., Öztürk, F., Tokat, F., 2006. Perivezikal paraganglioma: Olgu sunumu. Türk Üroloji Dergisi. 32, 433-435.

Soylu, L., Aydın, S., Alper SM, Atalay F., 2009. Retroperitoneal ekstraadrenal dev paraganglioma: Olgu sunumu. Ulusal Cerrahi Dergisi. 25, 178-180.

Tekin, A., Küçükkartallar, T., Vatansev, C., Aksoy, F., 2008. Nadir bir paraganglioma olgusu: Tiroid paraganglioması. Süleymen Demirel Tıp Fakültesi Dergisi. 15, 38-40. 